\title{
Unit of Amount of Substance
}

National Cancer Institute

\section{Source}

National Cancer Institute. Unit of Amount of Substance. NCI Thesaurus. Code C48453.

Physical quantity that measures the number of elementary entities in the object

compared with the number of elementary entities (atoms, molecules, ions, electrons, or particles) in 0.012 kilogram of pure carbon- 12 . 